\title{
Toxic Substances Use and Juvenile Violence in Ivory Coast: The Case of Young Adults and Adolescents in Conflict with the Law, Known as "Microbes"
}

\author{
Konan Koffi Paulin", Traore Brahim Samuel", ", Kouassi Ettien Silvie ${ }^{3}$, Aka Rita Ahou², \\ Yeo-Tenena Yessonguilana Jean-marie ${ }^{2}$ \\ ${ }^{1}$ Addiction and Mental Hygiene Service, National Institute of Public Health, Abidjan, Ivory Coast \\ ${ }^{2}$ Medical Sciences Training and Research Unit, Félix Houphouët Boigny University, Abidjan, Ivory Coast \\ ${ }^{3}$ Center Marguerite Te Bonle, National Institute of Public Health, Abidjan, Ivory Coast
}

Email address:

kk420408@gmail.com (K. K. Paulin),samygrande@live.fr (T. B. Samuel), silvie.kassi@gmail.com (K. E. Silvie), rita_aka@yahoo.fr (A. R. Ahou), ouandete@gmail.com (Yeo-Tenena Y. Jean-marie)

${ }^{*}$ Corresponding author

\section{To cite this article:}

Konan Koffi Paulin, Traore Brahim Samuel, Kouassi Ettien Silvie, Aka Rita Ahou, Yeo-Tenena Yessonguilana Jean-marie. Toxic Substances Use and Juvenile Violence in Ivory Coast: The Case of Young Adults and Adolescents in Conflict with the Law, Known as "Microbes". American Journal of Psychiatry and Neuroscience. Vol. 9, No. 2, 2021, pp. 44-49. doi: 10.11648/j.ajpn.20210902.14

Received: March 7, 2021; Accepted: April 29, 2021; Published: May 8, 2021

\begin{abstract}
At the end of a post-electoral crisis in 2011, urban delinquency in Ivory Coast is undergoing a deep change. Young adults and teenagers attack the population according to a triptych that signs a particular modus operandi. An interpretation of this criminality, which is foreign to the taxonomy of delinquency, attempts to situate the place of toxic substances in the criminal actions of those whom the population calls "microbes". This was a cross-cutting study lasting three (03) months. Based on the exhaustive sampling technique, 123 subjects out of 583 young people in conflict with the law enrolled in a resocialisation and reintegration project in 2020, were selected. The respondents were all male, aged 10-25 years old and all out of school. They were all polydrug users, with prevalences of $98.37 \%$ for cannabis and $95.12 \%$ and $91.87 \%$ respectively for psychotropic drugs diverted from their therapeutic use and alcohol. Their criminal trajectory revealed offences of theft in meetings $(100 \%)$ and assault and battery $(84.55 \%), 15.45 \%$ of which led to death. Ritualisation was noted in the preparation of the assaults and in their execution; the first stage being conditioning by the consumption of a "psychoactive cocktail", the second: acting in a gang, and finally the third stage: execution of a scene of murderous violence with knives and unusual weapons $97.28 \%$ (machete, axe and human bones). Criminal intentionality presides over the act in the case of "microbes". Drug use only serves to convey a feeling of omnipotence and an increase in cortical excitement. It thus responds to a ritualisation imbued with symbolic signifiers and constitutes a preparatory conditioning for planned predatory violence. The traditional tandem drug and crime should not be the only explanatory approach to all criminal violence among drug users.
\end{abstract}

Keywords: Juvenile Delinquency, Drugs, Microbes, Predatory Violence, Ivory Coast

\section{Introduction}

The hypothesis of a link between the use of psychoactive substances and the perpetration of acts of violence, particularly among young people, is often raised in several studies. Numerous surveys conducted among a youth population known to have already committed violent acts (whether or not they were prosecuted) have reported high rates of drug and alcohol use among these young people [1-3] Young people who use illicit drugs are twice as likely to be involved in a violent act compared to young people of the same age who do not report such use [4]. Beyond the link, however, these violent acts raise questions about the place of these toxic substances in criminal behaviour. Thus, as an inducer of criminal intent, a catalyst of criminal behaviour or a conditioning tool for the act, toxins are indexed as a determinant of violence in certain delinquent populations. In 
Côte d'Ivoire, the so-called "microbes" crystallize the debates on this issue. Indeed, at the end of the post-electoral crisis of 2011 that this country went through, juvenile delinquency has undergone a deep change. These young people, nicknamed "the microbes", attack the population with murderous violence. They constitute a social group where two types of behaviour coexist, with multiple and sometimes complex links: the use of toxic substances and murderous violence. To explain the existence of a supposed link between the use of psychoactive substances and the violence observed in this group of young people, we will rely on the first, psychopharmacological postulate of Goldstein's conceptual model [5] and the conceptual model developed by Brunelle, Brochu and Cousineau [6]. The first, psychopharmacological postulate is based on the intoxication of the offender. It is then estimated that the effect produced by the absorption of a substance would be at the origin of the criminal act, which would not have occurred otherwise [7]. Indeed, several authors agree that certain drugs have the property of acting on specific centres of the nervous system where the centres of aggressiveness, impulsiveness and inhibitions are located [8]. Qualitative work on the deviant trajectories of young people provides a slightly different picture for them [6]. Thus, young people are more inclined than adults to resort to intoxication with psychotropic products in order, among other things, to give themselves the courage to commit acts of delinquency. The aim of this work was to study the place of toxic substances in the passage of hetero-aggressive acts of these populations in conflict with the law.

\section{Materials and Method}

This is a cross-sectional study involving 123 respondents from 583 young people in conflict with the law, who were participating in a resocialisation and reintegration project initiated by the Ivorian government. The study and the resocialisation internship duration were both three (03) months. Based on the exhaustive sampling technique, 123 subjects out of 583 were selected, namely $21.09 \%$. Data collection was carried out using structured individual interviews conducted using a specially designed face-to-face questionnaire. The inclusion criteria were as follows: to have been tested positive for psychoactive substances; to have participated in at least one physical assault (assault and/or homicide); to have taken part in individual listening sessions proposed by the psychological monitoring team and to be mentally stable for the interview.

\section{Results}

\subsection{Socio-demographic Characteristics}

All our respondents were male, were in gangs and were between 10 and 25 years old. The majority of these young people came from Abobo, Yopougon and Adjamé, some popular townships of the city of Abidjan. In 79.68\% of cases they belonged to family types (single-parent, polygamous, reconstituted) whose internal dynamics could be a source of conflict. A proportion of $50.90 \%$ of them lived either on the street or with friends. At the time of the survey, they all had dropped out of school, but $89.09 \%$ had attended school. In terms of employment, $57.72 \%$ of these young people were unemployed and $42.28 \%$ were working in the informal sector or were in the process of learning a trade.

\subsection{Criminal and Judicial Data}

The results of our survey showed that the crime of theft was committed by all of our respondents. In addition, more than $3 / 4$ or $84.55 \%$ of them were the perpetrators of assault and battery inflicted on others which resulted in death in $15.45 \%$ of cases. The weapons used during these assaults were $97.28 \%$ cold weapons (machete, axe and human bones). At the judicial level, $31.71 \%$ had a previous record of imprisonment or had already been taken into police custody after being arrested by the police.

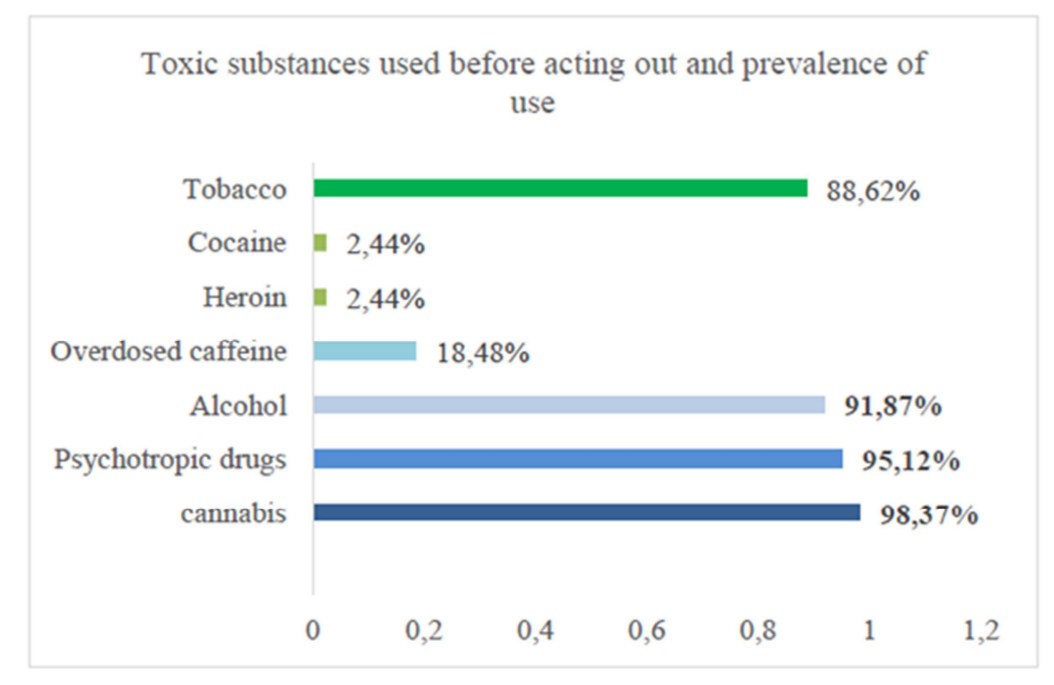

Figure 1. Prevalence of use of toxic substances among respondents. 


\subsection{Prévalence of Toxic Substances Used Prior to the Violence Committed}

The results of the toxicological analyses of urine for psychoactive substances combined with the declarations of toxic substances use during interviews with the respondents showed a higher prevalence of use of three toxic substances. These were respectively cannabis (98.37\%), psychotropic drugs diverted from their therapeutic use (95.12\%) and alcohol $(91.87 \%)$. These drugs were used systematically before any hetero-aggression acting out.

\subsection{Attributability of Toxic Substances in the Violence Committed}

The individual interviews conducted with these young people showed that in $89.43 \%$ of them, the motivation to use drugs was a tenfold effect of courage and a "doping" effect of aggressiveness, allowing them to take action. In fact, these were regular uses which were ritualised before the acting out of hetero-aggressive violence, through the consumption of a "psychoactive cocktail" made up of alcohol and psychotropic drugs diverted from their therapeutic use (Clonazepam, Diazepam and Tramadol) and cannabis. This conditioning before any action is taken is well illustrated in the verbatim statements of some respondents, expressed in Ivorian popular language, which will also be the subject of a semantic analysis.

\subsection{Collection of Verbatim from Participants}

Verbatim 1: "Alcohol and drugs allow me to have one heart to be able to act".

Verbatim 2: "Without my doses my mind is scattered, before going to act out I take four cans of energy drink with my tablets plus my doses of drugs (kalé). After that my mind becomes one and I can go for it.»;

Verbatim 3: "Without my dose, I cannot have big heart to do what I have to do ";

Verbatim 4: "With clear eyes, I cannot take a knife to prick or stab anybody, I would have to be cut (drugged enough)".

It should be noted, however, that $10.57 \%$ of them said that they did not need to take these toxic substances in order to act out.

\section{Discussion}

All our respondents were male, were in gangs and were between 10 and 25 years old. Of these young people, $57.72 \%$ were unemployed and $42.28 \%$ were working in the informal sector or in the process of being apprenticed. Yves MARGUERAT's study on: "Les jeunes délinquants d'Abidjan" reported fairly similar results. This study in fact showed that young delinquents or predelinquents in Abidjan constituted a homogeneous group in terms of gender $(95.2 \%$ boys) and age (75.6\% between 15 and 18 years old), with no activity in half of the cases [9].

These young adults and adolescents came mainly from
Abobo, Yopougon and Adjamé some popular townships of the city of Abidjan. $79.68 \%$ of them belonged to three types of family structure: single-parent, polygamous or blended, and were able to justify regular consumption of toxic substances. By approaching drug use through the prism of family conformation, our results are in line with those of a recent quebecker survey on tobacco, alcohol, drugs and gambling among secondary school students. This survey showed that the proportion of students who used drugs over a twelve-month period is higher among those living in a singleparent family structure than among those living in a twoparent family structure $(38.5 \%$ vs. $24.1 \%)$ [10]. The internal dynamics of the family structure appears here as a probable risk factor related to this phenomenon.

At the time of the study, our respondents were all out of school, but $89.09 \%$ had attended school. The results of the urine test undertaken among these young people showed that $98.37 \%$ of them regularly used cannabis, with the majority of them starting to use it at a very young age, as indicated by the extremes of the age group. On this subject, Brook et coll. reported that cannabis use in early adolescence was a risk factor for dropping out of school [11]. Regular and prolonged cannabis use is associated with failure and dropping out of school [12]. In their recent systematic review on substance use and school drop-out, Townsend et coll. note that a significant association between early cannabis use and school drop-out has been identified in several longitudinal studies. These authors also point out that dropping out of school is a complex phenomenon in which several variables may be involved, such as ethnicity, gender and motivation to perform. It is not possible to highlight the unique effect of drug use on school drop-out [13]. However, Hall argues that cannabis use interferes with learning ability and academic achievement, and that difficulties at school are in turn a risk factor for dropping out and cannabis use [14]. Finally, Kalant also correlated school failure with the frequency of cannabis use in adolescence and young adults [15].

These vulnerable adolescents were thus used as tools during the post-electoral crisis of 2010-2011 in Ivory Coast. From wandering "street children", they were recruited by adults as child soldiers, ammunition carriers for combatants or informants. They have experienced the atrocities of war at close quarters and have seen adults cross the moral boundaries they themselves set. These children have acquired the conviction that it is normal and possible to obtain what one wants through force and violence. At the end of the war they are once again left to live on their own. In order to survive on a daily basis, these children will use the disinhibition they acquired during the war years [16]. They then commit theft. Moreover, our study reveals that all of the respondents were concerned by this offence. $84.55 \%$ of them were perpetrators of assault and battery inflicted on others, $15.45 \%$ of which led to death. These crimes and misdemeanours exposed some of them to deprivation of liberty or legal proceedings. In fact, $31.71 \%$ of them were subjects to incarceration or arrest by the police. Despite the 
repressive policy, groups of "microbes" children are multiplying with in the city of Abidjan. Some "microbes" children who are immediately captured come out of prison more determined and more violent than before. As Gérard Mauger argues: "We know that the threat of crime reinforces the solidarity of the delinquent group and imprisonment encourages its transition from occasional to professional delinquency" [17]. The nature of the weapons used: $97.28 \%$ of cold weapons (machetes, axes) and atypical weapons (human bones from desecrated graves) illustrate the intentionality and level of aggression that feeds their passage to action.

Just as the world of crime is closely linked to the world of drug trafficking, so professional delinquency is rarely considered without toxic substances use. The results of the urine test and the interviews on the use of toxic substances showed that the respondents were all polydrug users. The prevalence of toxic drug use was $98.37 \%$ for cannabis, $95.12 \%$ for psychotropic drugs diverted from their therapeutic use and $91.87 \%$ for alcohol. The high proportions of cannabis and alcohol use are similar to those found in the results of the study by Serge Brochu et coll. These authors found that more than nine out of ten offenders used alcohol and cannabis at least once [18]. However, one of the specificities of our results is that we note an equally high proportion $(95.12 \%)$ of drug use of medicinal origin. Speaking of the misuse of certain drugs as drugs, Isidore S. Obot stated that in an increasing number of West African countries, Tramadol and certain opioid substances have become very popular drugs among young people [19]. The use of syrups containing codeine or dextromethorphan have become quite common in these populations.

On the basis of the psychopharmacological postulate of Goldstein's conceptual model [5] and the conceptual model developed by Brunelle, Brochu and Cousineau [6], the individual interviews conducted with these young people showed that in $89.43 \%$ of them, the motivation for using drugs was conditioning to act, seeking an emboldening and doping effect of aggressiveness. In reality, before committing aggression, these individuals indulged in the consumption of cocktails made of alcohol and tablets (Clonazepam, Diazepam, Tramadol, etc.), codeine syrups or syrups containing dextromethorphan to which they added cannabis. Thus, as the first postulate attests, we can go in the same direction as Ben Amar, by arguing that it is the effect of the toxic substances which have the property of acting on specific centres: the centres of aggressiveness, impulsiveness and inhibitions [8]. In this context, we agree with some authors that the effect produced by the absorption of a substance would be at the origin of the criminal action, which would not otherwise have taken place [7]. Intoxication brings with it a series of cognitive disturbances that cause the repertoire of responses to be narrowed. The primary responses include aggressiveness and violence. However, if we take the reflection further, we identify the limits of this postulate in the notion of criminal intentionality. For some people, intoxication is a tool, as well as a weapon, which makes it possible to carry out a gesture that is difficult to commit while fasting. The substance is therefore consumed with the avowed purpose of committing an act that would otherwise be impossible. An analysis of the verbatim reports obtained during interviews with the respondents finds arguments in favour of the latter hypothesis.

Verbatim 1: "Alcohol and drugs allow me to have one heart to be able to act".

In Ivorian popular language, "to have one heart" means to have stability in decision-making, to be firm in one's will to act, to be determined to act, not to give up. Here the respondent shows that toxic substances have a conditioning effect before the act is carried out. The analysis of the second verbatim gives a rather similar interpretation.

Verbatim 2: "Without my doses my mind is scattered, before going to act out I take four cans of energy drink with my tablets plus my doses of drugs (kalé). After that my mind becomes one and I can go for it. »;

The word "Kalé " is the local name for cannabis. Here the respondent indicates that in order to be firm in his will to act, to be determined to act without fear and to be bold, he must consume a cocktail of energy drinks, psychotropic drugs diverted from their therapeutic use and cannabis. Without this cocktail, he says, "my mind is scattered". Here the word "scattered" brings us back to notions such as: being disturbed, lack of serenity.

Verbatim 3: "Without my dose, I cannot have big heart to do what I have to do ";

In Ivorian jargon "big heart" means having courage. The respondent asserts that he has a "dose", i.e. toxic substances to be consumed before any action is taken. Without these substances he lacks courage. The emboldening effect is therefore sought through the consumption of toxic substances, which brings us back to the same principle of conditioning before acting. The last verbatim deals with a motivation for close use with a small nuance.

Verbatim 4: "With clear eyes, I can't take a knife to prick or stab someone, I would have to be cut".

"In the same jargon, to be cut means to be under the effect of toxic substances, to be in a state of drunkenness. It can be alcoholic drunkenness, cannabic drunkenness or other. Conversely, the term "clear eyes" brings us back to lucidity, to a state where judgment is not impaired. In this case, the respondent was reporting a freely consensual choice to get into a state of intoxication and thus to alter his or her own judgment, in order to surrender to using a weapon against a person.

Ubsequent to the analysis of these verbatim, we note that the toxicants were used for a conditioning effect before the hetero-aggressive acting out. A fortiori for $89.43 \%$ of them, criminal action requires a modified state of consciousness and an adapted level of aggressiveness and courage. The psychoactive cocktails they consume would help them to achieve this. As some authors have argued, young people are more inclined than adults to resort to intoxication with psychotropic products in order, among other things, to give themselves the courage to commit acts of delinquency [6]. 
The abuse of certain psychotropic drugs leads to the commission of more serious criminal acts than those committed by a person who is sober or who does not abuse these substances [20,21]. Ritualisation has been observed in the preparation of assaults and in their execution, reproducing a characteristic modus operandi. The first stage was the preparation for action by the consumption of a "psychoactive cocktail". The distinction between public rituals during emotional violence and private rituals associated with predatory violence is deliberately concealed from the target of the aggression; and despite its stereotypical nature, the private ritual is more permeated with symbolic and almost magical meanings than the public ritual of emotional violence. The aim of private ritual in predatory violence is not to reduce or eliminate a perceived threat, but to gratify certain pathognomonic narcissistic desires that generally remain unconscious. In preparation for predatory violence, the individual may select certain objects, such as clothing, trinkets, jewellery, amulets, unusual weapons (...) which increase his sense of grandeur. The private ritual may also include the use of drugs, usually psychostimulants, which also increase feelings of grandiosity and omnipotence. The drug is physically held and controlled by the subject, it can be used or left aside according to needs, it carries the subject's grandiose projections, it can be absorbed on demand its chemical properties create a subjective state of selfconfidence, a feeling of omnipotence and an increase in cortical excitement [22]. The verbatim analysis above is to be added to this explanatory approach.

Secondly, there was gang action with purpose to act with cold weapon, 97.28\% (machete, axe and human bones) and thirdly, the execution of a scene of murderous violence. All observers of the phenomenon agree on the decisive influence of the Brazilian film "The City of God" shot in a favela in Brazil where a young hero, Zé Pequeňo [23], ends up imposing himself through violence in a very poor urban environment: the underprivileged youth of Abidjan identify themselves to this child from the favela and dream of as an urban heros reigning with terror [24]. In this same film production, co-directed by Fernando Meirelles and Kátia Lund, we see children attacking adults in gangs [23]. According to other sources, the term "microbes" comes from the fact that they are still small in number but still pose a threat. In both cases this group predation reproduces the style of predation of the object of identification. Predatory aggression typically results in the destruction of the prey. The type of weapon used by the subjects in our sample reflects the intention to destroy the assaulted persons. The use of cold weapons such as machetes and axes is disproportionate, if it is only a matter of removing property from other people under threat. But among these weapons, human bones fuelled by the desecration of graves are probably the most unusual weapons used to increase their sense of omnipotence over death and the fear they inspire. Predatory aggression, and in particular predatory violence in humans, has certain characteristics (...) It is a matter of planned and premeditated violence, due to this ritualised modus operandi, in a gang with this type of weapon. In fact, predatory violence is intentional, consciously planned and directed towards a goal. It is a one-sided activity rather than one triggered by a perceived threat. It is intentional in the sense that the predator chooses the timing of the violence, its victim and its intensity. It will have been understood that the psychopathic process was particularly adapted to predatory behaviour and that consequently, the subjects of our study could present a psychopathic mode of functioning. The emergence of heteroaggressive violence cannot therefore be completely attributed solely to the use of Psychoactive Substances (drugs). As proof, $10.57 \%$ of them did not feel the need to use these toxic substances before committing an act.

\section{Conclusion}

The analysis of the criminal action of the "microbes" shows that the triptych that signs their modus operandi responds to a ritualisation and a fantasy of repetition of the scene. This private ritual is more penetrated by symbolic signifiers and constitutes a preparatory conditioning for planned predatory violence. The ritual here includes the use of drugs, which conveys grandiose projections and creates a subjective state of self-confidence, a feeling of omnipotence and an increase in cortical excitement. According to J. Reid Meloy, the primary goals of predatory violence can be determined by factors such as membership in youth gangs, criminal gangs or sub-cultures that disinhibit aggression and function as primary catalysts [22]. Criminal intentionality thus presided over the act of "microbes". The act of predation and its violence, while attracting media attention and catalysing fear in the population, reinforces an oversized self of individuals with a psychopathic mode of functioning. Thus the traditional tandem drug and crime should not be the only explanatory approach to all violence in organized crime. Subsequent studies on this issue may improve sampling techniques and reduce selection bias to ensure greater inclusiveness. It should also include an assessment of the personalities of the subjects studied so that a clear split can be highlighted between the antisocial behaviors of a normal drug user personality and the psychopathic personality mode of functioning. Finally, screening for symptoms of psychotrauma should be systematic. From these results, a best psycho-légal support and sociotherapy care can be offered without obscure a prevention of this juvenile phenomenon.

\section{Conflicts of Interest}

The authors declare that they have no conflict of interest.

\section{References}

[1] Braithwaite, R. L., Cornely, R. C., Robillard, A. G., Stephens, T. T. et Woodring, T. (2003). Alcohol and other drug use among adolescent detainees. Journal of Substance Use and Misuse. 8 (2): 126-131. 
[2] Hammersley, R., Marsland, L. et Reid, M. (2003). Substance use by young offenders: The impact of the normalisation of drug use in the early years of the $21 \mathrm{sr}$ century. London, G.-B.: Home Office Research Study, 104 p.

[3] Rainon, G. A., Schmeidler, J. W., Frank, B. et Smith, R. B. (2006). Violent behavior, substance use, and other delinquent behaviors among middle and high school students. Youth Violence and Juvenile Justice. 4 (3): 247-265.

[4] Substance Abuse Mental Health Services Administration (SAMHSA). (2006). Youth Violence and Illicit Drug Use. The NSDUH. Report 5. Retrieved 26 March 2021, from https://files.eric.ed.gov/fulltext/ED495798.pdf.

[5] Goldstein, P. J. (1985). The drug/Violence Nexus: A tripartite conceptual framework. Journal of Drug Issues. 15 (4): $493-$ 506.

[6] Brunelle, N., Brochu, S., Cousineau, M. M. (2000). Drugcrime relations among drug-consuming juvenile delinquents: A tripartite model and more. Contemporary drug problems. 27 (4): 835-866.

[7] Weiner, M. D., Sussman, S., Sun, P. et Dent, C. (2005). Explaining the link between violence perpetration, victimization and drug use. Addictive Behaviors. 30 (6): 1261-1266.

[8] Ben Amar, M. (2007). Psychotropic criminogenic drugs. Criminology, 40 (1), 11-30. Retrieved March 26, 2021 from https://doi.org/10.7202/016013ar.

[9] Marguerat, Y. (1985). Young offenders from Abidjan: a first quantitative approach. Cah. ORSTOM, ser. Sci. Hmm, vol. XXI, nos 2-3, p. 373-379.

[10] Cazale, L., Fournier, C., \& Dubé, G. (2009). Consumption of alcohol and drugs. In Quebec survey on tobacco, alcohol, drugs and gambling among high school students (pp. 91-147). Quebec: Institute of Statistics of Quebec.

[11] Brook, J. S., Balka, E. B., \& Whiteman, M. (1999). The risks for late adolescence of early adolescent marijuana use. American journal of public health, 89 (10), 1549-1554. Retreived 26 March 2021, from https://doi.org/10.2105/ajph.89.10.1549.

[12] Paglia-B., A. \& Adlaf, E. (2007). Substance Use, Harms and Youth. In Canadian Center on Substance Abuse (Ed.), Substance Abuse in Canada: Spotlight on Young People (pp. 4-13). Ottawa.

[13] Townsend, L., Flisher, A. J., \& King, G. (2007). A systematic review of the relationship between high school dropout and substance use. Clinical child and family psychology, 10, 295317.

[14] Hall, W. D. (2006). Cannabis use and the mental health of young people. Australian and New Zealand Journal of Psychiatry, 40, 105-113.

[15] Kalant, H. (2004). Adverse effects of cannabis on health: an update of the literature since 1996. Prog Neuropsychopharmacol Biol Psychiatry, 28, 849-863.

[16] Julie Baudryard O. (2018). Juvenile crime: "germ" children as a symptom of the difficulties of child protection in the Ivory Coast Practical sociologies 2 (37): 141-142.

[17] Mauger, G. (2009). The sociology of juvenile delinquency. Paris: The discovery. https://doi.org/10.3917/dec.mauge. 2009.01.

[18] Brochu, S., Cousineau, M.-M., Provost, C., Erickson, P. et Fu, S. (2010). When drugs and violence meet among young people: an explosive cocktail? Drugs, Health and Society, 9 (2): $149-178$.

[19] Obot IS. (2016). Drug use and its effects on young people in West Africa. Uyo: Center for Research and Information on Drug Addiction (CRISA).

[20] D'Orsonnens, L. L. (2000). Substance abuse and juvenile delinquency. Intervention, 111, 81-88.

[21] Kerber, L. \& Harris, R. (1998). Substance use among female inmates Texas department of criminal justice - Institutional division: 1998. Austin (TX): Commission on Alcohol and Drug Abuse.

[22] Reid Meloy J. (2015). The Psychopaths: An Essay in Dynamic Psychopathology. Ed. Frison-Roche (pp187-197). Paris.

[23] Darién Davis. (2002). Cidade De Deus [City of God]. Directed by Fernando Meirelles; co-directed by Kátia Lund; produced Walter Salles; screenplay by Bráulio Mantovani. Brazil. 2002; color; 132 minutes. Distributed by Miramax Films. The American Historical Review, 107 (5): 1684-1685, https://doi.org/10.1086/ahr/107.5.1684.

[24] Ofpra Information, Documentation and Research Division (2017). The groups of microbes in Abidjan: the functioning of the gangs and the policy of struggle of the authorities. Accessed March 26, 2021 from https://www.ofpra.gouv.fr/sites/default/files/atoms/files/1702 civ_microbes.pdf. 